\title{
Effect of Thyroxine on Exophthalmos in Thyrotoxicosis
}

\author{
D. A. KOUTRAS,* M.D. ; W. D. ALEXANDER, $\dagger$ M.D., M.R.C.P.GLASG., M.R.C.P.ED. ; \\ W. W. BUCHANAN, $\dagger$ M.D., M.R.C.P.GLASG., M.R.C.P.ED. ; R. MCG. HARDEN, $\dagger$ M.B. ; \\ R. D. HUNTER, $\ddagger$ M.B., F.R.C.S.ED., F.R.C.S.GLASG.
}

Brit. med. F., 1965, 1, 493-495

Exophthalmos is found in approximately $75 \%$ of patients with thyrotoxicosis (Buchanan et al., 1962). In a few patients the exophthalmos is severe and associated with chemosis, periorbital oedema, and ophthalmoplegia (Brain, 1959), whereas in the majority of patients the exophthalmos is of mild degree and constitutes little more than a cosmetic problem. The distinction between these two forms of exophthalmos is, however, arbitrary, since the mild form may occasionally progress to the severer variety (Werner, 1960). There is a tendency for both mild and severe exophthalmos to increase after treatment of thyrotoxicosis, whether by surgery (Bartlett, 1962), radioiodine (Hamilton et al., 1960), or antithyroid drugs (Beierwaltes, 1948 ; Alexander et al., 1961), although clinical recognition of this tendency may be masked in the milder form by improvement in other eye signs such as lid-retraction (Hales and Rundle, 1960).

Thyroxine has been claimed to be of benefit in the treatment of severe exophthalmos (McCullagh et al., 1958). It has been suggested that thyroxine might also be of value in preventing increase in exophthalmos when administered along with antithyroid drugs in the treatment of thyrotoxicosis (Fraser, 1956 ; Bergfelt et al., 1961). In the present paper we have studied the effect of L-thyroxine on the exophthalmos of thyrotoxic patients treated with antithyroid drugs or radioiodine.

\section{Materials and Methods}

Sixty-eight thyrotoxic patients were studied. In each case the diagnosis was made on clinical grounds (Crooks et al., 1959) and confirmed by both serum P.B.I. estimations (Farrell and Richmond, 1961) and radioiodine studies. None of the patients had severe or malignant exophthalmos and none developed this condition during the course of the study. The patients were treated with either radioiodine or antithyroid drugs, and these two categories were each randomly subdivided into two groups, one having antithyroid therapy alone and the other antithyroid therapy and thyroxine.

Group 1.-This group consisted of 13 patients (10 females, and 3 males) aged 18 to 53 years. They were treated with antithyroid drugs, either potassium perchlorate in an initial dose of $1 \mathrm{~g}$. daily divided into four doses or carbimazole $40-60 \mathrm{mg}$. daily in four divided doses. When the patients became euthyroid maintenance doses of potassium perchlorate 250$500 \mathrm{mg}$. or carbimazole 7.5 to $15 \mathrm{mg}$. daily were used.

Group 2.-This group consisted of 23 patients (18 females and 5 males) aged 18 to 51 years. They were treated as in group 1 , but in addition received L-thyroxine sodium $0.2 \mathrm{mg}$. daily throughout the study.

Group 3.-This group consisted of 16 patients (15 females and 1 male) aged 49 to 60 years. They were treated with radioiodine, using the dosage-prescribing procedure described by Crooks et al. (1960a). They were selected from a larger

\footnotetext{
* Formerly University Department of Medicine, Western Infirmary, Glasgow. Now at Athens University Department of Clinical Therapeutics.

University Department of Medicine, Western Infirmary, Glasgow.
$\ddagger$ University Department of Ophthalmology, Western Infirmary, Glasgow.
}

group studied by including those patients who became euthyroid with one dose and remained euthyroid for at least a further three months.

Group 4.-This group consisted of 16 patients (14 females and 2 males) aged 45 to 63 years. They were treated with radioiodine as in group 3 , but in addition received L-thyroxine sodium $0.2 \mathrm{mg}$. daily throughout the study. They were selected from a larger group studied by including those patients who became euthyroid with one dose.

Exophthalmometer readings were made, using Zeiss-Hertel and Luedde instruments. In general, the two readings were in close agreement and statistical analysis was therefore performed only on the Zeiss-Hertel results. The study was arranged so that the physician who carried out the exophthalmometry was unaware of the treatment group to which the patient had been allocated. Exophthalmometry was performed prior to starting treatment, when the patient became euthyroid, and three months later. The patient's progress was followed at monthly intervals, using the therapeutic index of Crooks et al. (1960b) and estimations of the serum P.B.I. The patients were regarded as euthyroid when the therapeutic range lay between 0 and 5 and when in those not receiving thyroxine the serum P.B.I. lay within the normal range.

\section{Results}

The results are summarized in the Table and the Chart.

\begin{tabular}{|c|c|c|c|c|c|}
\hline \multirow{3}{*}{ Group } & \multirow{3}{*}{$\begin{array}{c}\text { No. } \\
\text { of } \\
\text { Cases }\end{array}$} & \multicolumn{2}{|c|}{ Control Value } & \multirow{2}{*}{ 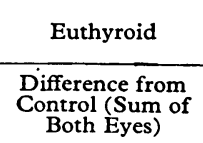 } & \multirow{2}{*}{$\begin{array}{c}\begin{array}{c}\text { Three Months } \\
\text { (Euthyroid) }\end{array} \\
\begin{array}{c}\text { Difference from } \\
\text { Control (Sum of } \\
\text { Both Eyes) }\end{array}\end{array}$} \\
\hline & & Right Eye & Left Eye & & \\
\hline & & $\begin{array}{l}\text { Mean } \pm \\
\text { S.E. }(\mathrm{mm} .)\end{array}$ & $\begin{array}{l}\text { Mean } \pm \\
\text { S.E. (mm.) }\end{array}$ & $\underset{(\mathrm{mm} .)}{\operatorname{Mean} \pm \text { S.E. }}$ & $\underset{(\mathrm{mm} .)}{\operatorname{Mean} \pm \text { S.E. }}$ \\
\hline 1 & 13 & $17 \cdot 4 \pm 0.52$ & $17 \cdot 3 \pm 0.62$ & \multirow{4}{*}{$\begin{array}{l}+1.5 \pm 0.57 \\
t=2.63, P<0.025 \\
+1.7 \pm 0.65 \\
t=2.62, P<0.02 \\
+0.9 \pm 0.70 \\
t=1.29, P<0.3 \\
-0.3 \pm 0.75 \\
t=0.4, P>0.6\end{array}$} & \multirow{4}{*}{$\begin{array}{l}+2.4 \pm 0.49 \\
t=4.90, P<0.001 \\
+2.5 \pm 1.01 \\
t=2.48, P<0.05 \\
+2.0 \pm 0.53 \\
t=3.77, P<0.0025 \\
+0.1 \pm 0.71 \\
t=0.14, P>0.8\end{array}$} \\
\hline 2 & 23 & $17 \cdot 7 \pm 0 \cdot 49$ & $18.0 \pm 0.50$ & & \\
\hline 3 & 16 & $17.6 \pm 0.65$ & $17.6 \pm 0.68$ & & \\
\hline 4 & 16 & $18.1 \pm 0.77$ & $17 \cdot 7 \pm 0.79$ & & \\
\hline
\end{tabular}

The 13 patients in group 1 were euthyroid on average 12 weeks after starting treatment. By that time the exophthalmos had increased in eight patients, had decreased in three, and remained unchanged in two. The mean change (sum of both eyes) from the control value $(+1.5 \pm 0.57 \mathrm{~mm}$.) was statistically different from zero $(P<0.025)$. By a further three months the exophthalmos had increased in all but one of the patients, the mean change, $+2.4 \pm 0.49 \mathrm{~mm}$. being significantly different from zero $(\mathrm{P}<0.001)$.

The 23 patients in group 2 were euthyroid on average after 13 weeks. This is not significantly different from the time of becoming euthyroid in group 1. At this time there was an increase in exophthalmos in 17 , no change in 4 , and a decrease in 2 . The mean difierence, $+1.7 \pm 0.65 \mathrm{~mm}$., was significantly 
different from zero $(P<0.02)$. Three months later the proportion of patients with an increase in the exophthalmos was unchanged and the mean change, $+2.5 \pm 1.01 \mathrm{~mm}$., was significantly different from zero $(P<0.05)$.

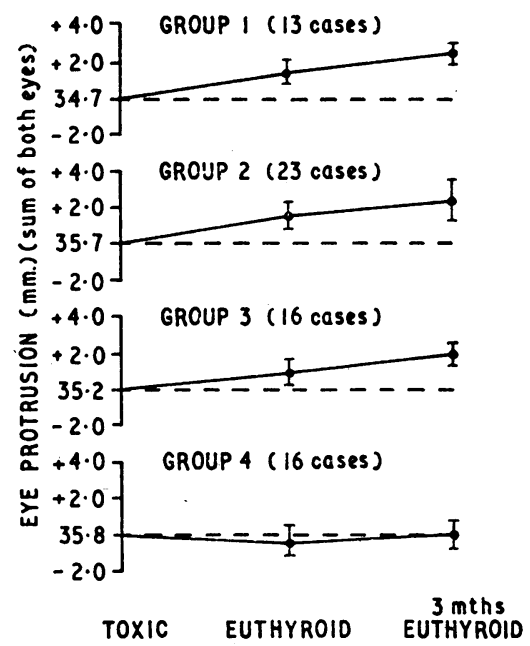

Effect of treatment on exophthalmos in thyrotoxic patients.

The 16 patients in group 3 were euthyroid on average 10 weeks after administration of the dose. At that time and three months later in all but two patients the exophthalmos had increased. This change, $+0.9 \pm 0.70 \mathrm{~mm}$. when the patient first became euthyroid, was not significantly different from zero $(0.2<\mathrm{P}<0.3)$, but three months later had increased significantly, $+2.0 \pm 0.53 \mathrm{~mm}$. $(P<0.0025)$.

The 16 patients in group 4 were, on average, euthyroid by 11 weeks. This is not significantly different from the time of becoming euthyroid in group 3. At this time the exophthalmos had decreased in four, increased slightly in five, and remained unchanged in seven. The mean change from the control value, $-0.3 \pm 0.75 \mathrm{~mm}$., was not significantly different from zero. Three months later exophthalmos showed a decrease in five, a slight increase in five, and no change in six. The mean change, $+0.1 \pm 0.71 \mathrm{~mm}$., was again not significantly different from zero.

No significant difference was found when the increases in the degree of exophthalmos in the first three groups were compared. In group 4 the change was, however, significantly less than that in the other three groups. When compared with group 3 the difference in the changes was not significant $(0.2<\mathrm{P}<0.3)$ when the patients first became euthyroid but were significantly less three months later $(P<0.05)$. The difference was even more pronounced when this group was compared with groups 1 and 2 both when euthyroid and three months later.

\section{Discussion}

Thyroid hormones have often been used, and varying claims made regarding their efficiency, in the treatment of severe or malignant exophthalmos. Their use along with antithyroid drugs in the treatment of mild exophthalmos associated with thyrotoxicosis has also been recommended (Fraser, 1956; Bergfelt et al., 1961), although some workers have doubted their value (Werner, 1960). The rationale of this treatment is also far from clear. There is no evidence in thyrotoxicosis that thyroxine suppresses the thyroid gland uptake of radioiodine (Greer and Smith, 1964 ; Werner and Spooner, 1955) or the pituitary output of thyroid-stimulating hormone or exophthalmos-producing substance. On the other hand, if hypothyroidism develops during treatment of thyrotoxicosis it is well known that exophthalmos may increase, and under these circumstances thyroxine may well be effective.
Elsewhere we have shown that D-thyroxine given with methylthiouracil does not prevent the increase in exophthalmos that occurs when methylthiouracil is given alone (Alexander et al., 1961). In the present investigation we have compared in a controlled study the course of mild exophthalmos in thyrotoxic patients treated with antithyroid drugs alone and with antithyroid drugs plus L-thyroxine sodium $0.2 \mathrm{mg}$. a day. There was no significant difference in the increase in exophthalmos between those two groups. None of the patients developed severe exophthalmos, but as this occurs only rarely a study of much larger groups would be required to determine the frequency of this complication either with or without thyroxine administration.

Treatment of thyrotoxicosis with radioiodine resulted in a smaller increase in exophthalmos than in the groups treated with antithyroid drugs, although the differences were not statistically significant. Ferguson (1951), using orbitonometry, found that exophthalmos progressed more slowly after radioiodine treatment than after administration of antithyroid drugs or surgery.

Thyroxine afforded protection against increase in exophthalmos in patients treated with radioiodine. The reason why this should be so is not clear. Patients with radioiodine were on average older than those treated with antithyroid drugs, but there was no significant difference between the pretreatment exophthalmometer readings in any of the groups studied. It is possible that antithyroid drugs may interfere with the peripheral action of thyroxine, and it has been shown that thiouracil compounds inhibit de-iodination of thyroxine (Herrera et al., 1963 ; Hershman, 1964), but there is no evidence that this applies to perchlorate. There is evidence that radioiodine-labelled thyroid hormones are concentrated in the pituitary (Taurog et al., 1956). " This might lead to diminished production of exophthalmos-producing substance, although this alone would not account for the difference between groups 3 and 4. According to Hales et al. (1961), the thyroid radioiodine uptake is suppressed by the administration of exogenous thyroid hormone, in some cases as early as six weeks after administration of a therapeutic dose of radioiodine. There may therefore be two factors operating to prevent an increase in output of exophthalmos-producing substance-firstly, concentration of radioiodine in the pituitary gland, and, secondly, suppression by exogenous thyroxine. Whatever the mechanism, L-thyroxine sodium appears to prevent an increase in exophthalmos occurring after ${ }^{131}$ I therapy for thyrotoxicosis, but confirmation of these observations would be desirable before it was given routinely as a supplement.

\section{Summary}

Sixty-eight thyrotoxic patients were divided into four groups ; those treated with antithyroid drugs alone, antithyroid drugs plus thyroxine, radioiodine alone, and radioiodine plus thyroxine. Exophthalmos was measured before treatment began, when the patient became euthyroid, and three months later. An increase in the exophthalmos was recorded in the first three groups. In the fourth group, treated by radioiodine plus thyroxine, no significant change occurred.

We wish to thank Professor Sir Edward Wayne, Professor W. J. B. Riddell, and Dr. J. Crooks for advice and criticism. The work has been supported by grants from the Secretary of State for Scotland on the recommendation of the Advisory Committee on Medical Research and from the Medical Research Council.

\section{REFERENCES}

Alexander, W. D., Koutras, D. A., Buchanan, W. W., and Crooks, J. (1961). Brit. med. F., 1, 1194.

Bartlett, W. (1962). Surg. Gynec. Obstet., 114, 173.

Beierwaltes, W. H. (1948). Arch. intern. Med., 81, 364. 
Bergfelt, G., Ljunggren, J. G., and Hedberg, K. (1961). Ұ. clin. Endocr., 21, 72 .

Brain, R. (1959). Lancet, 1, 109.

Buchanan, W. W., Koutras, D. A., Crooks, J., Alexander, W. D., Brass, W., Anderson, J. R., Goudie, R. B., and Gray, K. G. (1962). ₹. Endocr., 24, 115.

Crooks, J., Buchanan, W. W., Wayne, E. J., and Macdonald, E. (1960a). Brit. med. F., 1, 151.

Murray, I. P. C., and Wayne, E. J. (1959). Quart. F. Med., 28, 211.

- Wayne, E. J., and Robb, R. A. (1960b). Lancet, 1, 397.

Farrell, L. P., and Richmond, M. H. (1961). Clin. chim. Acta, 6, 620

Ferguson, W. J. W. (1951). Trans. Ophthal. Soc. U.K., 71, 737.

Fraser, R. (1956). Practitioner, 176, 600.

Greer, M. A., and Smith, G. E. (1954). F. clin. Endocr., 14, 1374.
Hales, I. B., Myhill, J., Oddie, T. H., and Rundle, F. F. (1961). Ibid., 21, 569.

and Rundle, F. F. (1960). Quart. 7. Med., 29, 113.

Hamilton, H. E., Schultz, R. O., and De Gowin, E. L. (1960). Arch. intern. Med., 105, 675 .

Herrera, E., del Rey, F. E., and de Escobar, G. M. (1963). Endocrino$\log y, 73,744$.

Hershman, J. M. (1964). f. clin. Endocr., 24, 173.

McCullagh, E. P., Clamen, M., Gardner, W. J., Kennedy, R. J., and Lockhart, G.'(1958). Ann. intern. Med., 48, 445.

Taurog, A., Harris, G. W., Tong, W., and Chaikoff, I. L. (1956). Endocrinology, 59, 34 .

Werner, S. C. '(1960). In Clinical Endocrinology, edited by E. B. Astwood, p. 210. Grune and Stratton, New York

_ and Spooner, M. (1955). Bull. N.Y. Acad. Med., 31, 137.

\section{Preliminary Communications}

\section{Superior Mediastinal Obstruction Treated with Demecolcine Followed by Radiotherapy*}

Brit. med. F., 1965, 1, 495-496

The increasing frequency of carcinoma of the bronchus in recent years has led to an increase in the incidence of one of the common complications of this disease-namely, superior mediastinal obstruction. This distressing condition is associated with a uniformly poor prognosis, but radiotherapy has been shown to have a beneficial effect.

It has been demonstrated by many workers, including Keck and Kaiser (1954) and Schär et al. (1954), that demecolcine (Colcemid) arrests the mitotic cycle of cells at metaphase by inhibiting the formation of the nuclear spindle. It has also been convincingly shown by Terasima and Tolmach (1961) that lower doses of radiation are needed to sterilize mammalian cells if they are irradiated at metaphase than at any other time. It seemed reasonable, therefore, to perform an investigation in which patients suffering from superior mediastinal obstruction due to carcinoma of the bronchus were given demecolcine, followed after a suitable time interval by radiotherapy.

\section{Method}

Patients suffering from superior mediastinal obstruction due to carcinoma of the bronchus were selected for this trial because all previously published accounts of the treatment of this condition (Szur and Bromley, 1956; Howard, 1961) showed a universally poor prognosis. Any improvement in these results would be more easily seen. The experiment consisted of two parts: (1) determination of the time interval elapsing between administration of demecolcine and maximum mitotic arrest; and (2) the treatment of patients suffering from superior mediastinal obstruction by demecolcine followed by radiotherapy after this time interval.

In order to determine the time interval the following method was used. Four patients with accessible tumours were selected. Two had squamous carcinoma of the cervix (Cases 1 and 2), one had an ulcerating secondary metastasis in the right supraclavicular fossa from a squamous carcinoma of the bronchus (Case 3), and the fourth had multiple skin metastases from an anaplastic carcinoma of the bronchus (Case 4).

\footnotetext{
* This investigation was carried out during the tenure of a Laura de Saliceto Studentship in Cancer Research awarded by the University of London.
}

In each of these patients a biopsy was taken, followed by the administration of $5 \mathrm{mg}$. of demecolcine by mouth. This was followed at two-hourly intervals by further biopsies, the final one being taken eight hours after the dose of demecolcine.

The biopsy specimens were fixed in Susa and stained with haematoxylin and eosin. One thousand cells were counted in each biopsy sample and the percentage of cells in metaphase was noted. The results are shown in Table I. It appeared from these results that the maximum mitotic arrest occurred four hours after administration by mouth.

TABLE I

\begin{tabular}{c|c|c|c|c|c}
\hline \multirow{2}{*}{$\begin{array}{c}\text { No. of Cells } \\
\text { Counted }\end{array}$} & $\begin{array}{c}\text { Hours After } \\
\text { Demecolcine }\end{array}$ & \multicolumn{4}{|c}{$\%$ of Cells in Metaphase } \\
\cline { 3 - 6 } & Case 1 & Case 2 & Case 3 & Case 4 \\
\hline 1,000 & 0 & 0 & 0 & 1 & 0 \\
1,000 & 2 & 3 & 2 & 4 & 3 \\
1,000 & 4 & 11 & 10 & 12 & 11 \\
1,000 & 6 & 7 & 6 & 2 & 3 \\
1,000 & 8 & 4 & 3 & 2 & 3 \\
\hline
\end{tabular}

There were 20 patients with superior mediastinal obstruction in this trial: six had had symptoms of bronchial carcinoma for less than 12 weeks, seven had had the symptoms for 12 to 26 weeks, and the other seven had had symptoms for longer than 26 weeks. There had been signs of obstruction for less than eight weeks in 13 patients, while seven had had symptoms of mediastinal obstruction for more than eight weeks. These figures are very similar to those reported in the series by Howard (1961).

Of the 20 patients, eight did not have a positive biopsy, in nine the growth was anaplastic or oat-cell, and in three it was squamous. This is similar to the series reported by Szur and Bromley (1956).

The radiotherapy was given with $240-\mathrm{kV}$ machines, and the mediastinum was irradiated to a dose of 2,400 rads in three weeks. Four hours before each treatment $5 \mathrm{mg}$. of demecolcine was given by mouth. Treatment was given on five days a week. Blood counts were carried out twice a week.

\section{ResUlts}

The results were assessed in terms of survival, as it was felt that this was the most reliable means of deducing whether the treatment regimen was an improvement on the previous methods.

Table II shows survival time in months from the start of treatment. It will be seen that $9(45 \%)$ of the patients were alive at six months. This compares with $20 \%$ in the series of Szur and Bromley (1956) and $26 \%$ in Howard's (1961) series. In both of these the dose of radiation delivered was 